\title{
Investigation of Change in Reading-Math-Science Literacy Scores in PISA Applications with Multivariate-Multilevel Model
}

\author{
Sule Otken (Corresponding author) \\ Ministry of Education, Ankara, Turkey \\ E-mail: sule.ayyildiz@hotmail.com \\ Duygu Anil \\ Hacettepe University, Ankara, Turkey \\ E-mail: duygu.anil73@gmail.com
}

\begin{abstract}
The aim of this study is to determine the variables of school and student level that significantly affect the math-reading-science performance of Turkish students participating in PISA 2009-2012-2015 applications. Within the scope of this aim, gender, type of program, educational status of parents, educational opportunities at home, educational resources at home, educational facilities at home, economic-social-cultural status index were used. Regarding school level, school size, computer usability index, teacher-student ratio were included in the model. For the purpose of the study, data of PISA 20092012-2015 Turkish students were analyzed using the Multilevel-Multivariate Regression Model. According to the findings, it was observed that there were differences in math-reading-science scores among the schools. PISA 2009-2012 Turkey application of students' math-reading and science scores together predictor as revealing the student level, respectively, parental education status of variables, home educational resources, and in PISA 2015 application maternal education level, it is determined that the economic-social-cultural situation is. In all three applications, it was found that gender was the variable that predicted mathematics and reading performance significantly. PISA 2009 school-level predictors of Turkey as meaningful to the students of math-reading and science scores along with the application variables were found to be the teacher-student ratio. For PISA 2012 and PISA 2015, it was found that the school level variable which predicted academic achievement significantly was the usability index of computers. Based on the findings of the research, it may be suggested to reduce the disparity in student achievement among schools. Studies can be done to regulate the students' educational environments at home.
\end{abstract}

Keywords: PISA, multivariate-multilevel model, academic achievement.

DOI: $10.7176 / J S T R / 5-11-10$

\section{PISA Uygulamalarında Okuma-Matematik-Fen Okuryazarlığı Puanlarındaki Değişimin Çok Değişkenli-Çok Düzeyli Model İle İncelenmesi}

\begin{abstract}
Özet
$\mathrm{Bu}$ araştırmanın amacı, PISA 2009-2012-2015 uygulamalarına katılan Türk öğrencilerin matematikokuma-fen performanslarını birlikte manidar olarak etkileyen okul ve öğrenci düzeyi değişkenlerin belirlenmesidir. Bu amaç kapsamında öğrenci düzeyi değişkenlerden cinsiyet, program türü, anne ve baba eğitim durumu, evdeki kültürel olanaklar, evdeki eğitimsel kaynaklar, ev olanakları, ekonomiksosyal- kültürel durum indeksi kullanılmıştır. Okul düzeyi ile ilgili olarak ise okul büyüklüğü, bilgisayarların kullanılabilirlik indeksi, öğretmen-öğrenci oranı modele dahil edilmiştir. Araştırmanın amacı doğrultusunda PISA 2009-2012-2015 Türk öğrencilerine ait veriler, Çok Düzeyli-Çok Değişkenli Regresyon Modeli kullanılarak analiz edilmiştir. Elde edilen bulgulara göre, okullar arasında öğrencilerin
\end{abstract}

78 | P a g e

www.iiste.org 
matematik-okuma-fen puanlarında farkların olduğu gözlenmiştir. PISA 2009-2012 Türkiye uygulamasına ait öğrencilerin matematik-okuma-fen puanlarını birlikte manidar olarak yordayan öğrenci düzeyi değişkenlerin sırasıyla baba eğitim durumu, evdeki eğitimsel kaynaklar, PISA 2015 uygulamasında ise anne eğitim durumu, ekonomik-sosyal-kültürel durum olduğu belirlenmiştir. Her üç uygulamada matematik ve okuma performansını manidar olarak yordayan öğrenci düzeyi değişkenin cinsiyet olduğu sonucu ortaya çıkmıştır. PISA 2009 Türkiye uygulamasına ait öğrencilerin matematikokuma-fen puanlarını birlikte manidar olarak yordayan okul düzeyi değişken ise öğretmen-öğrenci oranı olarak bulunmuştur. PISA 2012 ve PISA 2015 için akademik başarıyı manidar olarak yordayan okul düzeyi değişkenin bilgisayarların kullanılabilirlik indeksi olduğu ortaya çıkmıştır. Araştırma bulgularına dayanarak, okullar arası söz konusu öğrenci başarısındaki farklılığın azaltılması önerilebilir. Öğrencilerin evdeki eğitim ortamlarını düzenleyici çalışmalar yapılabilir.

Anahtar sözcükler: PISA, çok değişkenli-çok düzeyli model, akademik başarı.

\section{Problem Durumu}

Hızla gelişen ve değişen dünyada toplumların ihtiyaç ve beklentilerine uygun bireyler yetiştirmenin, uluslararası düzeyde tüm eğitim sistemlerinin amaçları arasında yer aldığı söylenebilir. Türk Milli Eğitim Sisteminin genel amaçlarından biri de 1739 sayılı Milli Eğitim Temel Kanununda da belirtildiği gibi, Türk Milletinin bütün fertlerinin; ilgi, istidat ve kabiliyetlerini geliştirerek gerekli bilgi, beceri, davranışlar ve birlikte iş görme alışkanlığı kazandırmak suretiyle hayata hazırlamak ve onların, kendilerini mutlu kılacak ve toplumun mutluluğuna katkıda bulunacak bir meslek sahibi olmalarını sağlamaktır. Böylece bir yandan Türk vatandaşlarının ve Türk toplumunun refah ve mutluluğu artacak; öte yandan milli birlik ve bütünlük içinde iktisadi, sosyal ve kültürel kalkınma desteklenerek hizlanacaktır.

Eğitim sistemleri, sosyal ve teknolojik geçişlerin tarihi dönemlerinde kökten bir değişim geçirmiştir. Örgün eğitimin ana hedefi, öğrencilerini, yaşamları boyunca kendilerini eğitmek için entellektüel araçlar, etkinlik inançları ve içsel ilgi alanları ile donatmak olmalıdır. Bu kişisel kaynaklar, bireylerin yeni bilgi edinmelerini ve kendi iyilikleri için ya da yaşamlarını daha iyi hale getirmeleri için gerekli olan becerileri geliştirmelerini sağlar (Bandura, 1995).

Son yıllarda, dünyadaki eğitim sistemlerinde geniş ölçekli değerlendirmeler yapılarak, farklı akademik alanlarda ve okullarda öğrenci sonuçlarını değerlendirme ve karşılaştırmaya yönelik bir eğilim görülmektedir. Uluslararası geniş ölçekli değerlendirmeler, eğitim kurumları veya sistemleri ile ilgili kararlar almak amacıyla politika yapıcılar ve yöneticiler için bilgi sağlamaktadır. Eksiklikleri (güçlü yanlarının yanı sıra) ortaya koyarak çoğu zaman ulusal sistemlerdeki reformların ve eğitim programlarının başlatıcıları olarak hareket etmektedir (Aydın, 2017; Deeber vd., 2014; Goldstein, 2004; Lenkeit, 2012).

Eğitim sistemlerinin etkisini ve yeterliliğini artırmak, eğitimin kalitesini gözlemlemek ve geliştirmek için birçok ülke geniş ölçekli sınavlara güvenmeye başlamıştır. Ayrıca kaliteyi ölçmek ve geliştirmek amacıyla harcanan çabalar, Avrupa'da eğitim sistemlerinde tartışmalara sebebiyet veren Uluslararası Öğrenci Değerlendirmesi Programı (PISA), Uluslararası Okuryazarlık Çalışması (PIRLS) ve Uluslararası Matematik ve Fen Eğilimleri Araştırması (TIMMS) gibi uluslararası araştırmaların sonuçlarıyla daha da artmıştır (Milli Eğitim Bakanlığı Strateji Geliştirme Başkanlığı, 2009).

PISA, öğrenci performansını değerlendirmek ve performans farklılıklarını açıklamaya yardımcı olabilecek öğrenci, aile ve kurumsal faktörler hakkında veri toplamak için kapsamlı uluslararası bir programdır. PISA'nın özelliklerinden biri, çok düzeyli modellemeyi kullanarak okul farklılıklarını hesaba katma girişimidir. Bu nedenle, örneğin öğrencinin, toplumsal cinsiyet, sosyal geçmiş ve önceki kazanım gibi faktörleri içeren çeşitli öğrenci özelliklerine ve ayrıca katılan okul veya okullarla ilgili özelliklere bağlı olduğu varsayılmaktadır. Bu tür faktörleri içeren istatistiksel bir modeli kullanırken, okullar arasında öğrenci ya da okul düzeyindeki özellikler tarafından hesaplanamayan varyasyonlar kalmaktadır (Goldstein, 2004). Öğrencilerin okullarda yuvalanması nedeniyle elde edilen veri yapısı, hiyerarşik bir yapıyı iki düzeyli olarak oluşturmaktadır.

Sosyal bilimlerde, iç içe geçmiş veri yapıları çok yaygındır. İç içe geçmiş veriler (ilişkili gözlemler), sosyal bilim araştırmalarında sıkça görüldüğü gibi, bireyler gruplar halinde bir araya getirildiğinde ortaya çıkar. Örneğin, aynı okuldaki öğrenciler farklı okullardan gelen öğrencilere göre daha benzer olacaktır (Stevens, 2009). Eğitimde birçok politika yapıcı için, eğitim araştırmalarının önemli bir rolü, öğrencinin performansını en etkili biçimde artıran okul düzeyi faktörlerini belirlemektir. Bu nedenle, politika yapıcılar ve politikalar düşük sosyoekonomik statüde (SES) ve dezavantajlı okullarda öğrenci çıktılarının iyileştirilmesine odaklanır (Marks, 2010). Sosyoekonomik durumun ve aile özelliklerinin özellikle başarı 
üzerindeki etkisi uzun zamandan beri eğitim araştırmalarında büyük ilgi görmüştür. Aile arka planı, büyük ölçekli değerlendirmelerdeki ilgi alanlarından sadece biridir (Brese ve Mirazchiyski, 2010). Dolayısıyla PISA çalışmasında; okul ve öğrenci düzeyinde akademik başarıyı etkileyen faktörlerin ayrıntılı olarak incelenmesi, farklı yıllarda performans farklılıklarının kaynağı olan değişkenlerin belirlenmesinin gerekliliği söz konusudur. Bu nedenle PISA 2009-2012-2015 Türkiye uygulamasında öğrencilerin matematik-okuma-fen okuryazarlığı başarı puanlarını manidar olarak etkileyen değişkenleri belirlemek adına her üç PISA uygulamasında ortak kullanılan öğrenci ve okul özelliklerinden yararlanılmıştır. Bu araştırma kapsamında öğrencilerin başarılarını etkileyen faktörler çok değişkenliçok düzeyli modeller kullanılarak incelenmiş ve öğrencilerin başarı farklılıklarına yer verilmiştir.

Türkiye için PISA uygulaması, bu uygulamaya katılan dünyada söz sahibi olan ülkeler arasındaki yerini görmesi açısından önem taşımaktadır. Bu çalışmada, Türkiye'de 15 yaş grubundaki öğrencilerin matematik-okuma-fen alanlarındaki performansı çok değişkenli bir sonuç şeklinde ele alınarak araştırma kapsamında belirlenen bazı değişkenler ile olan ilişkisinin çok değişkenli çok düzeyli modelleme yaklaşımı ile incelenmesi amaçlanmıştır. PISA uygulamasında matematik-okuma- fen okuryazarlığ birbiriyle ilişkili olup öğrencilerin akademik başarısını temsil etmektedir. Öğrencilerin akademik başarısıyla ilişkili olduğu düşünülen öğrenci ve okul düzeyi değişkenleri ortaya koymak amacıyla yapılan çalışmalar incelendiğinde, okul ve öğrenci özelliklerinin iç içe geçmiş olması nedeniyle çok düzeyli bir yap1 oluşturduğu görülmektedir. PISA uygulaması örneklemi çok düzeyli bir yapı göstermesi nedeniyle bu araştırmada okul ve öğrenci özelliklerinin akademik başarıya etkisi çok değişkenli çok düzeyli modeller kullanılarak incelenmiştir. Alanyazın incelendiğinde, öğrencilerin PISA uygulamasında matematik-okuma-fen performansını manidar olarak yordayan öğrenci düzeyinde cinsiyet, program türü, anne-baba eğitim durumu, evdeki eğitimsel kaynaklar ve kültürel olanaklar, sosyoekonomik durum değişkenleri ile okul düzeyinde okul büyüklüğü, öğretmen- öğrenci oranı ve bilgisayarların kullanılabilirlik indeksi değişkenleri kullanılarak yapılan çok sayıda karşılaştırmalı çalışmalar ve bu değişkenlerin matematik-okuma- fen başarısına olan etkisini araştıran tek düzeyli ve tek değişkenli olarak yapılan çalışmalar mevcuttur. Bununla birlikte tek düzeyli analizlerin sınırlılıkları ve çok düzeyli modellerin avantajları nedeniyle bu çalışmada çok değişkenli-çok düzeyli model yaklaşımı kullanılmıştır.

Araştırmanın, 2009-2012-2015 yıllarında yapılan PISA uygulamalarında matematik-okuma-fen performansı ile ilişkili öğrenci ve okul düzeyindeki faktörlerin belirlenmesi ve başarı farklılıklarının ortaya konulması, çok değişkenli çok düzeyli model kullanılarak incelenmesi açısından alanyazına katkı getireceği düşünülmektedir. Ayrıca bu çalışma, benimsenen yaklaşım göz önünde bulundurulduğunda, bir anlamda PISA 2009-2012-2015 Türkiye sonuçlarının ilişkisel olarak yıllara göre karşılaştırmasını sunmaktadır. Bununla birlikte öğrencilerin matematik-okuma-fen başarısının her PISA döngüsünde ayrı ayrı temele alındığ 1 PISA 2009-2012-2015 uygulamalarının birlikte analiz edilmesi, üç uygulama arasındaki değişimin gözlenerek matematik-okuma-fen okuryazarlığ hakkında bilgi vermesi açısından önemlidir. Türkiye'de ilk kez, PISA çalışmasının çok değişkenli olarak matematik-okuma-fen performansının birlikte değerlendirilmesi, çok düzeyli modellerle karşılaştırmalı olarak ele alınması, bu çalışmanın özgün yanını oluşturmaktadır.

Araştırma Yöntemi

$\mathrm{Bu}$ araştırmada iki ve daha fazla değişken arasındaki ilişkiler incelendiğinden araştırmanın türü yordayıcı korelasyonel araştırmadır. Korelasyonel araştırmalarda bağımsız değişkenin düzeyleri araştırmacı tarafından manipüle edilemez. Araştırmacı bağımsız değişkeni tanımlayabilir, ancak bu değişkenlerin düzeylerine (Tabachnick ve Fidell, 2013).Araştırmanın evreni, uygulamaların yapıldığı yıllarda Türkiye'de ve belirlenen diğer ülkelerde eğitim alan 15 yaş grubu öğrencileridir. Veri toplama aracı olarak PISA 2009-2012-2015 uygulamalarında yer alan matematik-okuma-fen bilişsel puanları ile öğrenci ve okul anketlerinden alanyazın taraması sonucunda belirlenen bazı değişkenler kullanılmıştır. Araştırma kapsamında kullanılmak üzere belirlenen düzey 1 değişkenleri, bilişsel puanlar ve öğrenci özelliklerinden oluşmaktadır. Araştırma kapsamında kullanılan düzey 2 değişkenleri ise okul anketlerinden elde edilmiştir. PISA 2009-2012-2015 verileri, PISA Türkiye veri tabanından internet aracılığıyla indirilerek araştırma kapsamında yapılacak analizlerde kullanılmak üzere, veri dosyaları hazırlanmıştır. Veri dosyaları oluşturulurken, öncelikle PISA 2009-2012-2015 öğrenci anketi ile okul anketinde her üç yıla ait PISA uygulamasında ortak maddeler ve boyutlar incelenmiştir. Bununla birlikte ilgili alanyazın taraması sonucunda öğrencilerin akademik performansıyla ilişkili olduğu görülen değişkenler tespit edilmiştir. Maddeler ve boyutlar belirlendikten sonra bu madde ve boyutlara ait belirli istatistiksel yöntemlerle türetilen indeks değerleri kullanılmıştır. Araştırma kapsamında kullanılmak üzere belirlenen değişkenler; cinsiyet, program türü, anne-baba eğitim durumu, ebeveyn eğitimine ilişkin indeksler, evdeki kültürel olanaklar-eğitimsel kaynaklar, ev olanakları, ekonomik-sosyal-kültürel durum,

80 | P a g e

www.iiste.org 
okul büyüklüğü, bilgisayarların kullanılabilirlik indeksi, öğretmen-öğrenci oranı olarak belirlenmiştir. Verilerin analizi iki aşamada gerçekleştirilmiştir. İlk olarak analizler için gerekli tüm varsayımlar test edilmiştir. Daha sonra ise Çok Değişkenli-Çok Düzeyli Doğrusal Modeller (Çok Düzeyli Regresyon Analizi) kullanılarak araştırmanın alt problemleri analiz edilmiştir. Analize başlamadan önce, söz konusu veri setinde karşılanması gereken varsayımlar; kayıp verilerin ve uç değerlerin olmaması, veri setinin normal dağılıma sahip ve doğrusal olması, çoklu bağlantılık probleminin olmamasıdır (Büyüköztürk, 2010; Hair vd., 2014; Kline, 2011; Tabachnick ve Fidell, 2013).Araştırma kapsamında incelenen PISA 2009-2012-2015 yıllarına ait öğrencilerin matematik-okuma-fen başarılarının okul ve öğrenci özellikleri ile ilişkisi Çok Değişkenli-Çok Düzeyli Doğrusal Modeller ile analiz edilerek belirlenmiştir. Verilerin düzenlenmesinde sosyal bilimler için istatistik paket programı ve Çok Değişkenli-Çok Düzeyli Doğrusal Modeller için Mplus 6.12 programı kullanılmıştır.

\section{Bulgular}

Araştırma kapsamında belirlenen 'PISA 2009-2012-2015 Türkiye uygulamalarında 15 yaşındaki öğrencilerin matematik-okuma-fen okuryazarlığı performansı okul içinde ve okullar arasında nasıl değişmektedir?' problemine dayalı olarak Tesadüfi Etkili Tek Yönlü Anova modeli oluşturulmuştur. Bu modele göre PISA 2009-2012-2015 Türkiye uygulamalarında okullar arasında öğrencilerin matematikokuma-fen puanlarında farkların olduğu gözlenmiştir. Her üç uygulamada da ortaya çıkan varyansın yarıdan fazlası okullar arasında var olan farklılıklardan kaynaklanmaktadır. İkinci alt problem 'PISA 2009-2012-2015 Türkiye uygulamalarında öğrenci düzeyinde hangi faktörler öğrencilerin matematikokuma-fen okuryazarlığı performansını etkilemesine önemli ölçüde katkıda bulunur?' için Tesadüfi Katsayılı Regresyon Modeli oluşturulmuştur. Modele cinsiyet, program türü, anne eğitim durumu, baba eğitim durumu, evdeki olanaklar, evdeki eğitimsel kaynaklar, ev olanakları, ekonomik-sosyal-kültürel durum değişkenleri eklenmiştir. Her üç uygulamada matematik ve okuma performansını manidar olarak yordayan öğrenci düzeyi değişken "cinsiyet olduğu sonucu ortaya çıkmıştır. Kız öğrencilerin okuma başarısının, erkek öğrencilerden daha yüksek olduğu belirlenmiştir. Her üç uygulamada fen performansını manidar olarak yordayan bir değişken bulunamamıştır.

Üçüncü alt problem 'PISA 2009-2012-2015 Türkiye uygulamalarında okul düzeyinde hangi faktörler öğrencilerin matematik-okuma-fen okuryazarlığı performansına önemli ölçüde katkıda bulunur?’ için Ortalamaların Bağımlı Değişken Olduğu Regresyon Modeli oluşturulmuştur. Modele okul büyüklüğü, bilgisayarların kullanılabilirlik indeksi ve öğretmen-öğrenci oranı değişkenleri dahil edilmiştir. PISA 2009-2012-2015 uygulamasında matematik performansını manidar bir şekilde yordayan okul düzeyi değişken bulunmamaktadır. PISA 2009-2012-2015 uygulamasında okuma ve fen performansını manidar bir şekilde yordayan okul düzeyi değişken “öğretmen-öğrenci oranı” değişkenidir.

\section{Tartışma- sonuç ve öneriler}

$\mathrm{Bu}$ araştırma öğrencilerin PISA uygulamalarında matematik-okuma-fen performansını manidar olarak etkileyen okul ve öğrenci düzeyinde değişkenlere ait kanıt sunmaktadır. Araştırma kapsamında belirlenen değişkenlerin dışında kalan diğer okul ve öğrenci düzeyi değişkenlerin öğrencilerin akademik performansı üzerindeki etkilerinin araştırılması önerilebilir.

Araştırmada iki düzeyli analizler çok değişkenli olarak yürütülmüştür. Üç düzeyli olarak, sınıf veya yerleşim birimi gibi düzeylerin modele eklenmesiyle öğrencilerin akademik performansının ilgili değişkenler tarafından nasıl yordandığına yönelik çalışmalar yapılabilir.

Araştırmanın sınırlılıklarından biri olarak, PISA uygulamasına ait kullanılan verilerin kesitsel olması söylenebilir. $\mathrm{Bu}$ nedenle öğrencilerin akademik performansı ile söz konusu değişkenlerin ilişkisi boylamsal araştırma deseniyle incelenebilir.

Boylamsal veriler ise örtük büyüme modeli gibi karmaşık çok düzeyli modeller ile analiz edilebilir. Bu çalışma kapsamında kullanılan okul ve öğrenci düzeyi değişkenleri, öğrencilerin matematik-okumafen performansındaki değişimin sadece bir bölümünü oluşturmaktadır. PISA uygulamalarında öğrencilerin akademik performansını manidar olarak yordayan diğer okul ve öğrenci düzeyi değişkenleri de araştırmaya dahil edilmesi önerilebilir. Ayrıca öğretmen ve okul anketlerinde yer alan diğer ilgili değişkenler çok düzeyli model kullanılarak incelenebilir.

\section{Kaynakça}

Abbott, L. M., Joireman, J. ve Stroh, H. R. (2002). The influence of district size, school size and socio economic status on student achievement in Washington: a replication study using hierarchical linear modeling. Washington School Research Center. 
Acar, T. ve Öğretmen, T. (2012). Çok düzeyli istatistiksel yöntemler ile 2006 PISA fen bilimleri performansının incelenmesi, Eğitim ve Bilim Dergisi, 37, (163).

Acar Güvendir, M. (2017). Uluslararası öğrenci değerlendirme programında öğrencilerin matematik okuryazarlıkları ile ev ve okul eğitim olanakları arasındaki ilişkinin belirlenmesi - PISA 2012, Mersin Üniversitesi Eğitim Fakültesi Dergisi, 13(1): 94-109.

Akay, E. (2017). Ortaokul öğrencilerinin TEOG başarısına etki eden faktörlerin çok düzeyli analizi, (yayımlanmamış doktora tezi) Osmangazi Üniversitesi, Eskişehir.

Aksu, G., Güzeller, C. O. ve Eser, M. T. (2017). Öğrencilerin matematik okuryazarlığ performanslarının aşamalı doğrusal model (HLM) ile incelenmesi: PISA 2012 Türkiye Örneği, Ĕgitim ve Bilim Dergisi, 42(191), 247-266.

Akyüz, G. ve Berberoğlu, G. (2010). Teacher and classroom characteristics and their relations to mathematics achievement of the students in the TIMSS. New Horizons in Education, 58(1), 7795.

Alacac1, C. ve Erbaş, A. K. (2010). Unpacking the inequality among Turkish schools: findings from PISA 2006, International Journal of Educational Development, 30, 182-192.

Altun, A. (2007). Türkiyedeki sekizinci sınıf ögrencilerinin ögrenci ve okula baglı özelliklerinin matematik başarısı ile ilişkisi, (yayımlanmamış doktora tezi) Ortadoğu Teknik Üniversitesi, Ankara.

Anagün, Ş. S. (2011). PISA 2006 sonuçlarına göre öğretme-öğrenme süreci değişkenlerinin öğrencilerin fen okuryazarlıklarına etkisi, Ĕ̌itim ve Bilim Dergisi, 36(162).

Anderson, J. O., Milford, T. ve Ross, P. S. (2008). Multilevel modeling with HLM: taking a second look at PISA, Quality Research in Literacy and Science Education, Springer Science + Business Media B.V.

Andrews, M. Duncombe, W. ve Yinger, J. (2002). Revisiting economies of size in American education: are we any closer to a consensus? Econ. Educ. Rev.; 21(3), 245-62.

Anıl, D. (2009). Uluslararası öğrenci başarılarını değerlendirme programı (PISA)'nda türkiye'deki öğrencilerin fen bilimleri başarılarını etkileyen faktörler, Eğitim ve Bilim Dergisi, 34(152).

Anıl, D. (2011). Türkiye'nin PISA 2006 fen bilimleri başarısını etkileyen faktörlerin yapısal eşitlik modeli ile incelenmesi. Kuram ve Uygulamada Ĕgitim Bilimleri, 11(3).

Arıcı, Ö. ve Altıntaş, Ö. (2014). PISA 2009 okuma becerileri yeterliklerinin sosyoekonomik alt yapı ve okul öncesi eğitime katılım açısından incelenmesi "Türkiye Örneği”, Ankara University, Journal of Faculty of Educational Sciences, 47(1), 423-448.

Atar, H. Y. ve Atar, B. (2012). Türk eğitim reformunun öğrencilerin TIMSS 2007 fen başarılarına etkisinin incelenmesi, Kuram ve Uygulamada Eğitim Bilimleri, 12(4), 2621-2636.

Aydın, M. (2017). TIMSS 2011 öğretmen ölçeklerinin faktör yapısının ve psikometrik özelliklerinin incelenmesi, Marmara Üniversitesi Atatürk Ĕ̈itim Fakültesi Eğitim Bilimleri Dergisi, 46: 21-36.

Aydın, B. (2016). Çok düzeyli modeller: sürekli değişken ile iki düzeyli model örneği ve R programı ile analizi. Ege Eğitim Dergisi, 17(2), 567 - 596

Bandura, A. (1995). Self-efficacy in changing societies, Cambridge University Press.

Bartholomew, D. J., Steele, F., Moustaki, I.ve Galbraith, J. I. (2008). Analysis of multivariate social science data. CRC Press, Taylor and Francis Group.

82 | P a g e

www.iiste.org 
Beaton, A. E. Postlethwaite, N. T., Ross, K. N., Spearritt, D. ve Wolf, M. R. (1999). The benefits and limitations of international educational achievement studies, International Institute for Educational Planning, UNESCO.

Beese, J. ve Liang, X. (2010). Do resources matter? PISA science achievement comparisons between students in the United States, Canada and Finland, Improving School, 13(3), 266-279.

Berberoğlu, G. ve Kalender, İ. (2005). Öğrenci başarılarının yıllara, okul türlerine ve bölgelere göre incelenmesi: ÖSS ve PISA analizi, Eğitim Bilimleri ve Uygulama, 4(7), 21-35.

Borman, G. D., ve Overman, L. T. (2004), Academic resilience in mathematics among poor and minority students, The Elementary School Journal, 104(3), 177-195.

Brese, F. ve Mirazchiyski, P. (2010). Measuring students' family background in large-scale education studies, paper for the 4th IEA International Research Conference July 1-3, Gothenburg, Sweden

Burckhart, P. (2014). On the factors influencing performance of Indonesian students in PISA http://philipp-burckhardt.com adresinden indirilmiştir.

Büyüköztürk, Ş., Kılıç Çakmak, E., Akgün, Ö. E., Karadeniz, Ş. ve Demirel, F. (2008). Bilimsel araştırma yöntemleri. Ankara: Pegem Akademi Yayınları.

Büyüköztürk, Ş. (2009). Sosyal bilimler için veri analizi el kitabı. Ankara: Pegem Akademi Yayınları.

Büyüköztürk, Ş., Şekercioğlu, G. ve Çokluk, Ö. (2010). Sosyal bilimler için çok değişkenli istatistik, SPSS ve LISREL uygulamalarl, Ankara: Pegem Akademi Yayınları.

Chi, S., Liu, X. Wang, Z. ve Han, W. S. (2018). Moderation of the effects of scientific inquiry activities on low SES students' PISA 2015 science achievement by school teacher support and disciplinary climate in science classroom across gender, International Journal of Science Education.

Chiu, M. M. ve McBride-Chang, C. (2006). Gender, context, and reading: A Comparison of students in 43 Countries. Scientific Studies of Reading, 10( 4), 331-362, DOI: 10.1207/s1532799xssr1004_1.

Chiu, M. M. ve Xihua, Z. (2008). Family and motivation effects on mathematics achievement: Analyses of students in 41 countries. Learning and Instruction, 18(4), 321-336.

Cotton, K. (1996). School size, school climate and student performance. Portland, OR: Northwest Regional Educational Laboratory.

Cohen, J., Cohen, P. West, S. G. ve Aiken, L. S.(2003). Applied multiple regression/correlation analysis for the behavioral sciences, Lawrence Erlbaum Associates, Publishers.

Cotton K. (1996). School size, school climate and student performance. School Improvement Research Series Computational.

Crane, J. (1996). Effects of home environment, SES and maternal test scores on mathematics achievement, The Journal of Educational Research, 89(5), 305-314.

Cremers, B. P. M. ve Kyriakides, L. (2008). The dynamics of educational effectiveness, Routledge.

Çakan, M. (2003). Geniş ölçekli başarı testlerinin eğitimindeki yeri ve önemi, Ĕgitim ve Bilim Dergisi, 28(128), 19-26. 
Çelebi, Ö. (2010). PISA 2006 Uluslararası Öğrenci Değerlendirme Programı'nda insan kaynakları ve fiziksel kaynakların öğrencilerin fen okuryazarlı̆̆ına olan etkisinin kültürlerarası karşılaştırılması, (yayımlanmamış doktora tezi) Orta Doğu Teknik Üniversitesi, Ortaöğretim Fen ve Matematik Alanları Öğretimi Bölümü, Ankara.

Çoker, E. (2009). Çok düzeyli regresyon modelleri ile çok düzeyli yapısal eşitlik modellerinin uygulamalı karşılaştırılması. (doktora tezi). Mimar Sinan Güzel Sanatlar Üniversitesi, Fen Bilimleri Enstitüsü, İstanbul. http://tez2.yok.gov.tr/ adresinden edinilmiştir.

Darmawan, N. G. (2016). Assessing the Quality and Equity of Student Performance in Five Southeast Asian Countries, in Thien, L. M., Razak, A. N., Keeves, P. J. ve Darmawan, G. N.(Ed). What can PISA 2012 data tell us? performance and challenges in five participating southeast asian countries.

Deeber, D., Buchholz, J., Hartig, J. ve Janssen, R. (2014). Student, school and country differences in sustained test-taking effort in the 2009 PISA reading assessment. Journal of Educational and Behavioral Statistics, 39(6), 502-523.

Demir, E. (2013). Kayıp verilerin varlığında çoktan seçmeli testlerde madde ve test parametrelerinin kestirilmesi: SBS Örneği. Ĕ̆itim Bilimleri Araştırmaları Dergisi, 3(2).

Demir, E. (2015). Türkiye'de on beş yaş grubu öğrencilerin matematik okuryazarlık becerileri ile ilişkili duyuşsal özellikleri. Ankara Üniversitesi Eğitim Bilimleri Fakültesi Dergisi, 48(2), 165 184.

Demir, İ., Kılıç, S. ve Ünal, H. (2010). Effects of students' and schools' characteristics on mathematics achievement: findings from PISA 2006, Procedia Social and Behavioral Sciences 2, 3099-3103.

Demirbaş, M. ve Yağbasan, R. (2004). Fen bilgisi öğretiminde, duyuşsal özelliklerin değerlendirilmesinin işlevi ve öğretim süreci içinde, öğretmen uygulamalarının analizi üzerine bir araştırma, Gazi Üniversitesi Kırşehir Ĕ̈itim Fakültesi Dergisi, 5(2), 177-193.

Demirel, Ö. (2007). Öğretimde planlama ve değerlendirme, Ankara: Pegem Akademi Yayıncılık.

Dewey, J. (1916). Democracy and education. New York: Free Press.

EARGED (2005). PISA 2003 projesi, ulusal nihai rapor. Ankara: Milli Eğitim Basımevi.

Eberts, R. W., Kehoe, E. ve Stone, J. A. (1984). The effect of school size on student outcomes, Center for Educational Policy and Management College of Education, 503, 686-5173.

ERG (2009). Türkiye’de öğrenci başarısında eşitsizliğin belirleyicileri

ERG (2017). PISA 2015: Genel bulgular ve eğilimler.

Ellez, A. M. (2004). Etkin ögrenme, strateji kullanımı, matematik başarısı, güdü ve cinsiyet ilişkileri, (yayınlanmamış doktora tezi) Dokuz Eylül Üniversitesi, İzmir.

Everitt, B. S. (2010). Multivariable modeling and multivariate analysis for the behavioral sciences. CRC Press. Taylor and Francis Group.

Field, A. (2009). Discovering statistics using SPSS. Sage Publications.

Finch, H. W. ve Bolin, E. J. (2017). Multilevel modeling using Mplus, CRC Press: Taylor and Francis Group. 
Fleischman, H.L., Hopstock, P.J., Pelczar, M.P., ve Shelley, B.E. (2010). Highlights from PISA 2009: performance of u.s. 15-year-old students in reading, mathematics, and science literacy in an international context (NCES 2011-004). U.S. Department of Education, National Center for Education Statistics. Washington, DC: U.S. Government Printing Office.

Friedman, L. (1989). Mathematics and the gender gap: a metaanalysis of recent studies on sex differences in mathematical tasks. Review of Educational Research, 59(2), 185-213.

Fuchs, T., ve Wößmann, L. (2007). What accounts for international differences in student performance? A re-examination using PISA data. Empirical Economics, 32: 433-464.

Geiser, C. (2010). Data analysis with Mplus. New York: Guildford Publication, Inc.

Gelman, A. ve Hill, J. (2007). Data analysis using regression and multilevel/hierarchical models. Cambridge University Press.

Giambona, F. ve Porcu, M. (2018). School size and students' achievement. Empirical evidences from PISA survey data, Socio-Economic Planning Sciences.

Goldstein, H. (2004). International comparisons of student attainment: some issues arising from the PISA study. Assessment in Education: Principles, Policy \& Practice, 11(3), 319-330.

Goldstein, H. (1999). Multilevel statistical models. London: Institute of Education.

Grilli, L., Pennoni, F., Rampchini, C. ve Romeo, I. (2016). Exploiting TIMSS and PIRLS combined data: multivariate multilevel modelling of student achievement, The Annals of Applied Statistics, 10(4), 2405-2426.

Guthrie, J. T. ve Greaney, V. (1991). Literacy acts. In R. Barr, M. L. Kamil, P. Mosenthal, \& P. D. Pearson (Eds.), Handbook of reading research, 2, 68-96. New York: Longman.

Gülleroğlu, H. D., Bilican-Demir, S. ve Demirtaşlı, N. (2014). Türk öğrencilerinin PISA 2003-20062009 dönemlerindeki okuma becerilerini yordayan sosyoekonomik ve kültürel değişkenlerin araştırılması, Ankara Üniversitesi Eğitim Bilimleri Fakültesi Dergisi, 47(2), 201-222.

Gürsakal, S. (2012). PISA 2009 öğrenci başarı düzeylerini etkileyen faktörlerin değerlendirilmesi, Süleyman Demirel Üniversitesi İktisadi ve İdari Bilimler Fakültesi Dergisi, 17(1), 441-452.

Güzel, İ.Ç. (2006). Uluslararası Öğrenci Değerlendirme Programı'nda (PISA 2003) insan ve fiziksel kaynakların ögrencilerin matematik okuryazarlı̆̆ına olan etkisinin kültürler arası karşılaştırılması, (yayımlanmamış doktora tezi) Orta Doğu Teknik Üniversitesi, Ortaöğretim Fen ve Matematik Alanları Öğretimi Bölümü, Ankara.

Hair, J. F., Black, W. C., Babin, J. B. ve Anderson, R. E. (2014). Multivariate data analysis (Seventh Edition). Pearson.

Hanushek. E. A., ve Woessmann, L. (2011). The economics of international differences in education achievement. In E. A. Hanushek, S. Machin, ve L. Woessmann (Eds.), Handbook of the Economics of Education (pp. 89-200). Elsevier: North Holland.

Heck, R. H. ve Thomas, L. S. (2015). An introduction to multilevel modeling techniques: MLM and SEM approaches using Mplus. Routledge.

Hek, M., Kraaykamp, G. ve Pelzer, B. (2017). Do schools affect girls' and boys' reading performance differently? A multilevel study on the gendered effects of school resources and school practices, School Effectiveness and School Improvement, https://doi.org/10.1080/09243453.2017.1382540 
Ho, E. S. C. ve Lam, T. Y. P. (2016). Multilevel analyses of families influence on adolescents literacy performances, International Journal Quantitative Research in Education, 3, 1 / 2, 58-78.

Hox, J. J. (2010). Multilevel analysis: techniques and applications (Second Edition). Routledge.

Hox, J. J. ve Roberts, J. K. (2011). Handbook of advanced multilevel analysis. Routledge.

Hyde, J. S., ve Linn, M. C. (2006). Gender similarities in mathematics and science. Science, 314, 599 -600 .

İnce, M. ve Gözütok, F. D. (2018). Anne-Babalarının Eğitim Durumlarının ve Evdeki Eğitim Kaynaklarının Öğrencilerin PISA Okuma Becerileri Test Sonuçlarına Etkisi, İlköğretim Online, 17(2), 947-958.

Johnson, R. A. ve Wichern, D. W. (2006). Multivariate analysis, Encyclopedia of Statistical Sciences.

Jones, I. ve White, S. (2000). Family Composition, Parent Involvement, and Young Children's Academic Achievement. Early Child Development and Care, 161, 71-82.

Kalaycı, Ş. (2014). SPSS Uygulamalı çok değiş̧kenli istatistik teknikleri. Ankara: Asil Yayıncılık.

Kalkınma Bakanlığı. (2014). Eğitim sisteminin kalitesinin artırılması, Özel İhtisas Komisyonu Raporu.

Karabay, E. Yıldırım, A. ve Güler, G. (2015). Yıllara göre PISA matematik okuryazarlığının öğrenci ve okul özellikleri ile ilişkisinin aşamalı doğrusal modeller ile analizi, Mehmet Akif Ersoy Üniversitesi Ĕgitim Fakültesi Dergisi, 36, 137-151.

Kelly, D., Xie, H., Nord, C.W., Jenkins, F., Chan, J.Y. ve Kastberg, D. (2013). Performance of U.S 15 year old students in mathematics, science, and reading literacy in an international context $\mathrm{U}$.S. Department of Education. Washington, DC: National Center for Education Statistics.

Kim, J., Anderson, C. J. ve Keller, B. (2014). Multilevel analysis of assessment data. Rutkowski L., Davier M. ve Rutkowski, D. (ed.) Handbook of international large scale assessment, CRC Press.

Kjærnsli, M. ve Molander, B. (2003). Scientific literacy: content knowledge and process skills. Lie, S., Linnakyla, P. ve Roe, A. (Ed.) Northern Lights on PISA, Department Of Teacher Education And School Development University Of Oslo, Norway.

Kjærnsli, M. ve Lie, S. (2011) Students' Preference for Science Careers: International comparisons based on PISA 2006, International Journal of Science Education, 33(1),121-144

Kline, R. B. (2011). Principles and practice of structural equation modelling. (Third Edition). New York: Guildford Publication, Inc.

Koğar, H. (2015). PISA 2012 Matematik okuryazarlı̆̆ını etkileyen faktörlerin aracıllk modeli ile incelenmesi. Eğitim ve Bilim, 40(179), 45-55.

Kotte, D., Lietz, P. ve Lopez, M. M. (2005). Factors influencing reading achievement in Germany and Spain: Evidence from PISA 2000, International Education Journal, 6(1), 113-124.

Kreft, G. G. I., de Leeuw, J. ve Aiken, L. S. (1995). The effect of different forms of centering in hierarchical linear models. Multivariate Behavioral Research, 30 (1).

Kuger, S., Klieme, E. Jude, N. ve Kaplan, D. (2016). Assessing contexts of learning an international perspective, Springer. 
Laere, V. E., Aesaert, K. ve Braak, V. J. (2014). The role of students' home language in science achievement: a multilevel approach, International Journal of Science Education, 36(16), 27722794.

Lam, T. Y. P. ve Lau, C. K. (2014). Examining factors affecting science achievement of Hong Kong in PISA 2006 using hierarchical linear modeling, International Journal of Science Education, $36(15), 2463-2480$.

Lara-Porras, M. A., Rueda-Garcia, M., Munoz, D. M. ve Rodriguez, B. C. (2018). Identifying the factors influencing the scientific competence in Andalusia: a multilevel study of the PISA 2012 results, The Eurasia Proceedings of Educational \& Social Sciences, 9, 200 -208.

Lee, Y. H. ve Wu, J. Y. (2012). The effect of individual differences in the inner and outer states of ICT on engagement in online reading activities and PISA 2009 reading literacy: Exploring the relationship between the old and new reading literacy, Learning and Individual Differences 22, $336-342$

Lenkeit, J.(2012). How effective are educational systems? A value-added approach to measure trends in PIRLS. Journal for Educational Research Online,4(2), 143-173.

Lenkeit, J. ve Caro, D. H. (2014). Performance status and change - measuring education system effectiveness with data from PISA 2000-2009, Educational Research and Evaluation, 20(2), 146174.

Lenkeit, J, Schwippert, K. ve Knigge, M. (2017). Configurations of multiple disparities in reading performance: longitudinal observations across France, Germany, Sweden and the United Kingdom, Assessment in Education: Principles, Policy \& Practice.

Lietz, P., Cresswell, J. C., Rust, K. F. ve Adams, R. J. (2017). Implementation of large-scale education assessments. Wiley Publication.

Li, H., Fortner, K. C. ve Lei, X. (2015). Relationships between the use of test results and US students' academic performance, School Effectiveness and School Improvement, 26 (2), 258-278.

Lin, Y. H., Chang, C. T., Lin, H. F. ve Wu, A. S. (2007). Analysis of HLM on PISA 2003 based on networked readiness index of countries and mathematics learning of students, 6th Wseas International Conference On Education And Educational Technology.

Liouaeddine, M., Bijon, M. ve Naji, F. (2017). The main determinants of moroccan students' outcomes, American Journal of Educational Research, 5(4) 367-383.

Lockheed, M., T. Prokic-Bruer, A. ve Shadrova, M. (2015). The experience of middle-income countries participating in PISA 2000-2015, OECD Publishing, Paris.

Mardia, K. V., Kent, J. T. ve Bibby, J. M. (1979). Multivariate analysis. Academic Press.

Marks, G. N. (2010). What aspects of schooling are important? School effects on tertiary entrance performance, School Effectiveness and School Improvement, 21(3), 267-287.

McCoach, B. D. (2010). Hierarchical Lineer Modelling, The reviewer's guide to quantitative methods in the social sciences, Ed: Gregory R. Hancock Ralph O. Mueller.

MEB (2010). PISA 2006 Uluslararası öğrenci değerlendirme programı ulusal nihai raporu. MEB, Ankara.

MEB (2010b). PISA 2009 Uluslararası ögrenci dĕgerlendirme programı ulusal ön raporu. MEB, Ankara. 
, No.11, 2019

MEB (2015). PISA 2012 Araştırması ulusal nihai rapor. Ankara: Milli Eğitim Basımevi.

MEB (2016). PISA 2015 Araştırması ulusal ön rapor. Ankara: Milli Eğitim Basımevi.

MEB (2018). Ĕgitim analiz ve değerlendirme raporları serisi, liselere geçiş sistemi merkezi sinavla yerleşen ögrencilerin performansı. Ankara: Milli Eğitim Basımevi.

Mertler, C. A. ve Reinhart, V. R. (2017). Advanced and multivariate statistical methods practical application and interpretation. (6th Ed.) Routledge.

Milli Eğitim Bakanlı̆̆ı Strateji Geliştirme Başkanlı̆̆1 (2009). Avrupa'da öğrencilerin ulusal ölçümü. hedefler, organizasyon ve sonuçların kullanımı. Ankara: Du ve Se Ajans.

Milli Eğitim Bakanlığı Strateji Geliştirme Başkanlığı (2011). Avrupa'da fen eğitimi: ulusal politikalar, uygulamalar ve araştırma.

Mislevy, R.J. (1995). What can we learn from international assessments? New Jersey: Educational Testing Service Princeton.

Mohammadpour, E. (2012) A Multilevel study on trends in Malaysian secondary school studentse science achievement and associated school and student predictors. Science Education, 6 (96), 1013-1046.

Mullis, V. S. I., Martin, O. M., Kennedy, A. M. ve Foy, P. (2007). PIRLS 2006 International Report, TIMMS and PIRLS International Study Center, Lynch School of Education: Boston College.

Muthen, L. K. ve Muthen, B. O.(2010). MPlus, statistical analysis with latent variables user's guide, (6th Ed.) Los Angeles, CA: Muthén \& Muthén.

Nagelkerke, N. J. D. (1991). A note on a general definition of the coefficient of determination, Biometrika,

Nagy, G., Nagengast, B., Frey, A., Becker, M. ve Rose, N. (2018). A multilevel study of position effects in PISA achievement tests: student- and school-level predictors in the German tracked school system, Assessment in Education: Principles, Policy \& Practice, DOI: 10.1080/0969594X.2018.1449100.

Nickell, B. K. (2003). Improving oral fluency, written accuracy and reading compherension in the $3 r d$ grade using visual art content. Master of Arts Action Research Project, Saint Xaiver Universiy, Chicago.

Nonoyama-Tarumi, Y. (2008). Cross-National Estimates of the Effects of Family Background on Student Achievement: A Sensitivity Analysis, International Review of Education, 54(1), 57-82.

Notten, N. ve Becker, B. (2017). Early home literacy and adolescents' online reading behavior in comparative perspective, International Journal of Comparative Sociology, 58(6) 475-493.

OECD (Organisation for Economic Co-Operation and Development) (2003). PISA 2003 assessment framework: mathematics, reading, science, problem solving, knowledge and skills, Paris: OECD Publishing.

OECD (2006). Assessing scientific, reading and mathematical literacy a framework for PISA 2006, Paris: OECD Publishing.

OECD (2007). PISA 2006 science competencies for tomorrow's world volume 1: analysis, Paris: OECD Publishing. 
OECD (2009a). PISA 2009 assessment framework key competencies in reading, mathematics and science, Paris: OECD Publishing.

OECD (2009b). Top of the class high performers in science in PISA 2006, Paris: OECD Publishing.

OECD (2009c). PISA 2006 technical report, Paris: OECD Publishing.

OECD (2010a). PISA 2009 at a glance, Paris: OECD Publishing.

OECD (2010b). Strong performers and successful reformers in education: lessons from PISA for the United States, Paris: OECD Publishing.

OECD (2010c). PISA 2009 results: overcoming social background - equity in learning opportunities and outcomes (volume II), Paris: OECD Publishing.

OECD (2013). PISA 2012 assessment and analytical framework: mathematics, reading, science, problem solving and financial literacy, Paris: OECD Publishing.

OECD (2014). PISA 2012 technical report. Paris: OECD Publishing.

OECD (2015). The ABC of gender equality in education: aptitude, behaviour, confidence, PISA, Paris: OECD Publishing.

OECD (2016). PISA 2015 assessment and analytical framework: science, reading, mathematic and financial literacy PISA, Paris: OECD Publishing.

OECD (2016b). PISA 2015 results (volume I): excellence and equity in education, PISA, Paris: OECD Publishing.

OECD (2017). PISA 2015 results (volume IV): students' financial literacy, PISA, Paris: OECD Publishing.

OECD (2017b). PISA 2015 results (volume III): students' well-being, PISA, Paris: OECD Publishing.

Ötken, Ş. ve Anıl, D. (2016). İlköğretim 7. sınıf başarısını yordayan değişkenlerin belirlenmesi, Anadolu Ĕgitim Liderliği ve Öğretim Dergisi, 4(1), 1-15.

Ovayolu, Ö. (2010). Türkiye'deki öğrencilerin PISA 2006 matematik alt testindeki düşünme ilişskin puan dağılımları, (yayımlanmamış yüksek lisans tezi) Ankara Üniversitesi, Eğitim Bilimleri Enstitüsü: Ankara.

Özberk, E. H., Atalay-Kabasakal, K., ve Boztunç-Öztürk, N. (2017). PISA 2012 matematik başarısını etkileyen faktörlerin hiyerarşik lineer model kullanılarak incelenmesi, Hacettepe Üniversitesi Eğitim Fakültesi Dergisi, doi: 10.16986/HUJE.2017026950.

Özkan, B. U. (2018). TIMSS-2015 sonuçlarının evde bulunan eğitimsel kaynaklar açısından karşılaştırmalı olarak değerlendirilmesi. Amasya Üniversitesi Eğitim Fakültesi Dergisi, 7(1), 98120.

Özkan, M. (2015a). Öğretmen yetiştiren programların giriş taban puanlarıyla KPSS ortalamaları arasındaki ilişkinin incelenmesi, Adıyaman Üniversitesi Sosyal Bilimler Enstitüsü Dergisi, 8(19).

Özkan, M. (2015b). PISA 2012 Türkiye verilerine göre okul değişkenlerinin öğrenci başarısını yordama gücü, Uluslararası Eğitim Bilimleri Dergisi, 2(5), 477-489.

Özer, Y. ve Anıl, D. (2011). Öğrencilerin fen ve matematik başarılarını etkileyen faktörlerin yapısal eșitlik modeli ile incelenmesi, Hacettepe Üniversitesi Eğitim Fakültesi Dergisi, 41: 315-324. 
Öztürk, Ö. (2018). PISA 2015 verileri kullanılarak, çevre bilinci ve çevre iyimserliğinin, fen okuryazarlı̆̆ ile ilişkisinin farklı sosyoekonomik düzeyler ele alınarak araştırılması, Yükseklisans Tezi, Bilkent Üniversitesi, Ankara, http://tez2.yok.gov.tr/ adresinden edinilmiştir.

Pamuk, S. (2014). Multilevel analysis of students science achievement in relation to constructivist learning environment perceptions, epistemological beliefs, self-regulation and science teachers characteristics, (yayınlanmış doktora tezi) Orta Doğu Teknik Üniversitesi, Ankara, http://tez2.yok.gov.tr/ adresinden edinilmiştir.

Polat, S. (2014). Türkiye’nin 2023 vizyonu ve eğitimde “orta kalite tuză̆ı”. SETA Yayınları.

Raudenbush, W. S. ve Bryk, A. S. (2002). Hierarchical linear models: applications and data analysis methods. London: Sage Publications.

Raudenbush, W. S, Rowan, B. ve Kang, S. J. (1991). A multilevel, multivariate model for studying school climate with estimation via the em algorithm and application to U. S. high-school data, Journal of Educational Statistics, 16 (4), 295-330.

Randolph, K. A. ve Myers, L. L. (2013). Basic statistics in multivariate analysis, Oxford University Press.

Reardon, S. ve A. Owens (2014), "60 years after brown: trends and consequences of school segregation”, Annual Review of Sociology, 40(1), 199-218.

Rencher, A. C. (2002). Methods of multivariate analysis. Wiley Publication.

Scheerens, J. ve Creemers, B.P.M. (1989). Conceptualizing school effectiveness. International Journal of Educational Research, 13, 691-706.

Schermelleh-Engel, K., ve Moosbrugger, H. (2003). Evaluating the fit of structural equation models: tests of significance and descriptive goodness-of-fit measures. Methods of Psychological Research Online, 8(2), 23-74.

Schulz, W. (2005). Measuring the socio-economic background of students and its effect on achievement in PISA 2000 and PISA 2003. American Educational Research Association, 7-11 April 2005.

Schoultz, J., Säljö, R. ve Wyndhamn, J. (2001). Conceptual knowledge in talk and text: what does it take to understand a science question? Instructional Science 29, 213-236.

Sebastian, J., Moon, J. ve Cunningham, M. (2016). The relationship of school-based parental involvement with student achievement: a comparison of principal and parent survey reports from PISA 2012, Educational Studies, DOI: 10.1080/03055698.2016.1248900.

Seber, G. A. F. ve Lee, A. J. (2003). Linear regression analysis, Wiley Publication.

Shafiq, N.M. (2013). Gender gaps in mathematics, science and reading achievements in Muslim countries: a quantile regression approach, Education Economics, 21(4), 343-359.

Shelley, M., ve Yildirim, A. (2013). Transfer of learning in mathematics, science, and reading among students in Turkey: A study using 2009 PISA data, International Journal of Education in Mathematics, Science and Technology, 1(2), 83-95.

Shera, P. (2014). School effects, gender and socio-economic differences in reading performance: a multilevel analysis. International Education Studies, 7(11). 
Silveira, F. (2018). The influence of foreign-born population on immigrants' academic achievement: a multilevel analysis of students in high-income countries, (yükseklisans tezi) Brigham Young Universitesi.

Sirin, S. R. (2005). Socioeconomic status and academic achievement: a meta-analytic review of research. Review of Educational Research, 75(3), 417-453.

Skrondal, A. ve Rabe-Hesketh, S. (2004). Generalized latent variable modeling multilevel, longitudinal, and structural equation models. CRC Press.

Snijders, T. A. B. ve Bosker, R. J.(2003). Multilevel analysis, an introduction to basic and advanced multilevel modeling. Sage Publications.

Stevens, J. P. (2009). Applied multivariate statistics for the social sciences (5th Ed.) Routledge.

Steenbergen, M. R. ve Jones, B. S. Modeling multilevel data structures, American Journal of Political Science, 46 (1), 218-237.

Suchodoletz, A. Larsen, R. A. A., Gunzenhauser, C. ve Fasche, A. (2015). Reading and spelling skills in german third graders: examining the role of student and context characteristics, British Journal of Educational Psychology, 85, 533-550.

Sun, L., Bradley, K. D. ve Akers, K. (2012). A multilevel modelling approach to investigating factors impacting science achievement for secondary school students: PISA Hong Kong sample, International Journal of Science Education, 34(14).

Şaşmazel, A. G. (2006). Uluslararası öğrenci değerlendirme programı'nda (PISA) Türk öğrencilerin fen bilgisi başarısını etkileyen faktörler, (yayımlanmamış yüksek lisans tezi) Hacettepe Üniversitesi, Ankara.

Şimşek, Ö. F. (2007). Yapısal eşitlik modellemesine giriş, temel ilkeler ve Lisrel uygulamaları, Ankara: Ekinoks Yayınları.

Tabachnick, B. G. ve Fidell, L. S. (2013). Using multivariate statistics (6th Ed.) Pearson.

Taht, K. ve Must, O. (2013). Comparability of educational achievement and learning attitudes across nations. Educational Research and Evaluation,19(1), 19-38.

Tatlıdil, H. (2002). Uygulamalı çok değişkenli istatistiksel analiz, Ankara: Akademi Matbaacılık.

Tekin, H. (1996). Ĕgitimde ölçme ve değerlendirme, Ankara: Yarg1 Yayınevi.

Thien, L. M. (2016). Malaysian Students' Performance in Mathematics Literacy in PISA from gender and socioeconomic status perspectives, Asia-Pacific Education Research, 25(4):657-666.

TEDMEM. (2014). PISA 2012: Türkiye üzerine değerlendirme ve öneriler.

Torppa, M., Eklund, K., Sulkunen, S., Niemi, P. ve Ahonen, T. (2018). why do boys and girls perform differently on PISA reading in finland? the effects of reading fluency, achievement behaviour, leisure reading and homework activity, Journal of Research in Reading, 41(1), 22-139.

Tunç, A. Ö., Ömür, A. G. ve Düren, A. Z. (2012). Çevresel farkındalık, Ístanbul Üniversitesi Siyasal Bilgiler Fakültesi Dergisi, 47, 227-246.

Turgut, M. F. ve Baykul, Y. (2010). Eğitimde ölçme ve değerlendirme, Ankara: Pegem Akademi Yayınc1lik. 
Türkan, A., Üner, S. S. ve Alcı, B. (2015). 2012 PISA matematik testi puanlarının bazı değişkenler açısından incelenmesi, Ege Eğitim Dergisi,16(2), 358-372.

Usta, H. G. (2014). PISA 2003 ve PISA 2012 Matematik okuryazarlı̆̆l üzerine uluslararası bir karşılaştırma: Türkiye ve Finlandiya, (yayınlanmış doktora tezi) Ankara Üniversitesi, Ankara, http://tez2.yok.gov.tr/ adresinden edinilmiştir.

Usta, H. G. ve Çıkrıkçı-Demirtaşlı, N. R. (2014). PISA 2006 sınavı sonuçlarına göre türkiye'deki öğrencilerin fen bilimleri okuryazarlığını etkileyen duyuşsal faktörler, Ĕgitim Bilimleri Araştırmaları Dergisi, 4(2).

Uzun, B. ve Öğretmen, T. (2010). Assessing the measurement invariance of factors that are related to students' science achievement across gender in TIMSS-R Turkey Sample, Eğitim ve Bilim Dergisi, 35 (155), 26-35.

Ünal, E. (2017). 2015 PISA sonuçlarına göre türk öğrencilerin evde sahip oldukları olanakların okuma becerisini yordama düzeyleri, International Journal Of Eurasia Social Sciences, 8(30), 1342-1356.

Van Laere, E., Aesaert, K. ve Van Braak, J. (2014). The role of students' home language in science achievement: a multilevel approach, International Journal of Science Education, 36 (16), 2772 2794.

Villa, P. N., Candelas, A. A., Neto, A. S., Franco, M. G. ve Melo, M. (2018). Academic achievement in physics-chemistry: the predictive effect of attitudes and reasoning abilities, Front. Psychol. 8:1064. doi: 10.3389/fpsyg.2017.01064.

Von Secker, C. E. ve Lissitz, R. W. (1999). Estimating the impact of instructional practices on student achievement in science. Journal Of Research In Science Teaching, 36(10).

Wolter, I., Braun, E. ve Hannover, B. (2015). Reading is for girls? The negative impact of preschool teachers' traditional gender role attitudes on boys' reading related motivation and skills, Front. Psychol.6:1267. doi: 10.3389/fpsyg.2015.01267.

Woltman, H., Feldstain, A., MacKay, C. J. ve Rocchi, M. (2012). An introduction to hierarchical linear modeling. Tutorials in Quantitative Methods for Psychology, 8(1).

Yalçın, S. ve Tavşancıl, E. (2014). Türk öğrencilerin pısa başarı düzeylerinin veri zarflama analizi ile yıllara göre karşılaştırılması, Kuram ve Uygulamada Ĕgitim Bilimleri, 14(3), 947-968.

Yerdelen, S. (2013). Multilevel investigations of students' cognitive and affective learning outcomes and their relationships with perceived classroom learning environment and teacher effectiveness, (yayınlanmış doktora tezi) Orta Doğu Teknik Üniversitesi, Ankara, http://tez2.yok.gov.tr/ adresinden edinilmiştir.

Y1lmaz, H. B. (2009). Turkish Students' scientific literacy scores: A multilevel analysis of data from program for international student assessment. Unpublished doctoral dissertation, The Ohio State University.

Yıldırım, Ö. (2017). Okul ortamlarının okuduğunu anlama performansı üzerinde etkisinin ülkeler arası incelenmesi, International Journal of Human Sciences, 14 (4).4453-4463.

Yolsal, H. (2016). Öğrencilerin sosyoekonomik ve kültürel statülerinin PISA 2012 başarıları üzerindeki etkisinin incelenmesi, Social Sciences Research Journal, 5(3), 7-27. 